\title{
THE EFFECT OF ACUTE ELEVATION OF BLOOD PRESSURE ON MYOCARDIAL PERFORMANCE DURING ENFLURANE AND ENFLURANE WITH NITROUS OXIDE ANAESTHESIA IN MAN*
}

\author{
P.C. DUKE, M. Morton AND S. Trosky
}

\begin{abstract}
Myocardial performance was assessed by a noninvasive method, when arterial pressure was raised acutely in eleven healthy subjects, awake and anaesthetized with equipotent (1 MAC) doses of either enflurane (Group 1) or enflurane with nitrous oxide 70 per cent. (Group 2). With anaesthesia, there was a significant and equal decrease in the indices of myocardial performance $(p<0.05)$ in both groups with pressure elevation when compared to awake controls. The results are similar to those observed in subjects with depressed myocardial function due to either ischaemic heart disease or halothane anaesthesia.
\end{abstract}

Key Words: Blood Pressure, peripheral vascular resistance; HeArT, myocardial function; ANAESTHETICS, Volatile, enflurane; ANA ESTHETICS, GASES, nitrous oxide.

THE PERFormance of the intact heart is normally regulated by the integration of three major determinants which govern the extent and velocity of shortening of the ventricular muscle and, thereby, stroke volume;' these are preload, afterload and contractile state of the myocardium. Afterload is a term which relates to active myocardial wall stress and impedance to systolic emptying. Increasing peripheral vascular resistance (which makes up the majority of outflow impedance) markedly affects ventricular function. ${ }^{1,2,12-15}$ Ross and Braunwald have shown that pressure "stressing" is a useful method of detecting impaired myocardial function in the clinical situation, particularly when there is no indication of such in the unstressed state. ${ }^{2}$ They observed that, following the administration of angiotensin, a normal heart was able to maintain a normal stroke volume, whereas a depressed or dysfunctioning heart did not.

In animals ${ }^{3}$ and $\operatorname{man}^{4}$ anaesthetized with

P.C. Duke, M.D., F.R.C.P.(C), F.A.C.A., As sociate Professor; M. Morton, M.B., B.S., F.F.A.R.C.S., Research Fellow; S. Trosky, R.N., Department of Anaesthesia, University of Manitoba Health Sciences Centre, Winnipeg, Canada.

Address Reprint Requests to: Dr. Peter C. Duke, Department of Anaesthesia, Health Sciences Centre, 700 William Avenue, Winnipeg, Manitoba, R3E $0 \mathrm{Z3}$.

*Presented at the annual meeting of The Canadian Anaesthetists' Society, June 1980. Supported by a grant from the Canadian Heart Foundation. 130 halothane it has been demonstrated that increasing vascular resistance resulted in significant decreases in stroke volume. Enflurane, alone or in a combination of nitrous oxide, produces myocardial depression similar to that of halothane. ${ }^{5-7}$ The purpose of this study was to observe the effects of increased vascular impedance on myocardial performance in man during equipotent levels of anaesthesia with enflurane and enflurane with nitrous oxide.

\section{Methods}

Eleven unmedicated healthy subjects ranging in age between 18 and 30 years were studied prior to undergoing minor surgical procedures (teeth extraction, nasal polypectomy, etc.). All studies were approved by our institutional human experimentation review committee.

Myocardial performance was assessed by using the non-invasive technique of systolic time intervals as described by Weissler, et $a l^{8}$ Systolic time intervals were measured from an electrocardiogram (lead 2), carotid artery pulse contour (surface transducer) and a precordial phonocardiogram. From a record as shown in Figure 1, the following intervals were measured. The $\mathrm{QS}_{2}$ represents the time for total electromechanical systole and is measured from the beginning of the QRS to the first high frequency vibration of the aortic component of the second heart sound. The LVET, or left ventricular

Can. Anaesth. Soc. J., vol. 29, no. 2, March 1982 


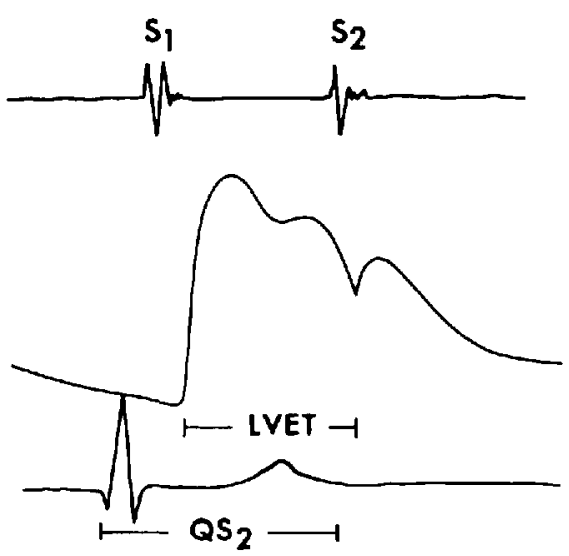

\section{Formulae}

PEP $=Q_{2}-L V E T$

PEP/ LVET

1/PEP 2

$$
E F=1.125-1.250
$$

\section{PEP/ LVET}

FIGURE 1 Measurements of systolic time intervals obtained from the phonocardiogram, carotid pulse wave, and electrocardiogram. The lower part of the figure shows the formulae for calculation of PEP and the derived intervals.

ejection time, represents the time from the initial upstroke of the carotid pulse to the trough of the incisural notch, i.e. the time between opening and closure of the aortic valve. The PEP or pre-ejection period is calculated by subtracting LVET from $\mathrm{QS}_{2}$ and represents the interval from beginning of ventricular depolarization to the beginning of left ventricular ejection. From these three measurements, three derived expressions have been shown to correlate with clinical invasive measurements (Figure 1). The PEP/ LVET ratio has the advantage of encompassing deviations of both intervals and reflects abnormality when neither measurement is clearly beyond normal. ${ }^{8}$ Depression of left ventricular function results in an increase in this ratio. $1 / \mathrm{PEP}^{2}$ has been shown by Reitan, et al. to correlate with peak ascending aortic blood flow, which is a good index of myocardial contractility. ${ }^{9}$ Ejection fraction derived from the formula $\mathrm{EF}=1.125-1.250 \times \mathrm{PEP} / \mathrm{LVET}$ has been shown by Garrard, et al. to have a close correlation ( $R=0.9$ ) with ejection fraction obtained by invasive measurements. ${ }^{10}$ All mea- surements were recorded at a paper speed of $100 \mathrm{~mm} / \mathrm{sec}$ on a Siemens Mingograph-800multi-channel jet ink recorder. All systolic time interval (STI) measurements were corrected for heart rate by Weissler's regression formula, ${ }^{8}$ and all values reported represent the mean of ten consecutive cardiac cycles.

Arterial pressure was measured directly from a radial artery catheter. In all awake subjects, with the STI apparatus in place, the arterial blood pressure was raised 2.66 to $5.32 \mathrm{kPa} \mathrm{(20}$ to 40 torr) by an intravenous bolus injection of angiotensin amide $2.5-10 \mu \mathrm{g}$. STIs were measured before the injection of angiotensin. When peak pressures were reached, STIs were recorded again (Figure 2). The STIs recorded during the awake period were designated the AWAKE CONTROL (AC) STIs and those recorded during the peak pressure response as the AWAKE PRESSOR (AP) STIs.

Following the awake measurements, the subjects were divided into two groups depending on the anaesthetic agent or agents administered. Group 1 consisted of six subjects who received 1 MAC or 1.86 per cent endtidal enflurane in oxygen. Group 2 consisted of five patients who received the equivalent of 1 MAC enflurane with 70 per cent nitrous oxide, that is, 0.56 per cent end-tidal enflurane. For each subject, anaesthesia was induced by face mask and the trachea was intubated without muscle relaxation. Ventilation was controlled and end-tidal (alveolar) carbon dioxide and enflurane were monitored continuously by infrared analysis. When the subjects were stabilized at the desired end-tidal enflurane concentrations, the same sequence of recording STI was followed as during the awake period; that is, the STI were measured before the administration of angiotensin and peak induced

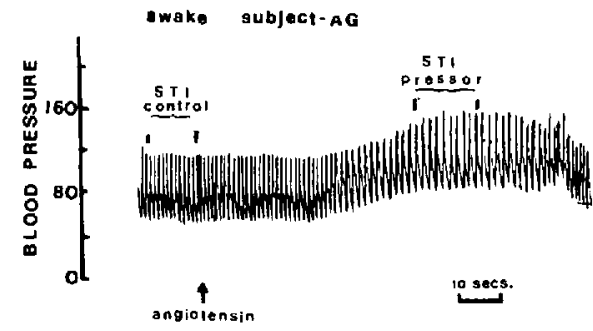

FIGURE 2 Blood pressure response before and after the injection of angiotensin $5 \mu \mathrm{g}$ in awake subject AC. Note the periods of the run in which systolic time intervals were calculated for the control (AC) and at peak pressure (AP) (see text). 
TABLE I

Blood Gas and Circulatory Data (Means \pm SD) for the Awake Controls and anaesthesia STUDIEs (Groups 1 and 2)

\begin{tabular}{|c|c|c|c|c|}
\hline & \multicolumn{2}{|c|}{ Group 1} & \multicolumn{2}{|c|}{ Group 2} \\
\hline & Awake Control & Enflurane $1.86 \%$ & Awake Control & $\begin{array}{c}\text { Enflurane } 0.56 \% \\
\text { and } 70 \% \mathrm{~N}_{2} \mathrm{O}\end{array}$ \\
\hline $\begin{array}{l}\text { SBP } \\
\mathrm{DBP} \\
\text { Heart Rate } \\
\mathrm{Pa}_{2} \text { (torr) } \\
\mathrm{PaCO}_{2} \text { (torr) } \\
\mathrm{pH}^{\text {H }}\end{array}$ & $\begin{array}{c}126.5 \pm 3.0 \\
61.5 \pm 4.0 \\
67.7 \pm 7.8 \\
94.5 \pm 8.6 \\
36.8 \pm 3.1 \\
7.43 \pm 0.02\end{array}$ & $\begin{aligned} 71.8 & \pm 8.9^{*} \\
42.7 & \pm 2.3^{*} \\
71.8 & \pm 5.6 \\
488.5 & \pm 59.3^{*} \\
36.5 & \pm 3.8 \\
7.42 & \pm 0.04\end{aligned}$ & $\begin{aligned} 134.9 & \pm 11.8 \\
67.8 & \pm 5.1 \\
68.8 & \pm 10.7 \\
88.8 & \pm 18.1 \\
33.2 & \pm 3.5 \\
7.42 & \pm 0.02\end{aligned}$ & $\begin{aligned} 90.1 & \pm 13.1^{*} \\
45.2 & \pm 5.6^{*} \\
68.8 & \pm 9.3 \\
126.5 & \pm 31.9^{*} \\
33.2 & \pm 3.0 \\
7.41 & \pm 0.03\end{aligned}$ \\
\hline
\end{tabular}

pressure change following its administration. The STI recordings were designated as the ENFLURANE CONTROL (EC) and the ENFLURANE PRESSOR (EP) STI respectively.

Statistical comparisons between the $A C$ and $A P$, the EC and EP measurements and derivations were compared to one another within each group and between groups by using analysis of variance and least significant difference testing. Values were considered significant when probability values were less than 0.05 .

\section{RESULTS}

Baseline blood pressure, heart rate, and blood gas data for both groups, awake and at $1 \mathrm{MAC}$ anaesthesia, are shown in Table I. As expected, blood pressure decreased with anaesthesia, although less in the Group 2 subjects who received nitrous oxide. $\mathrm{Pa}_{\mathrm{O}_{2}}$ increased significantly when $\mathrm{FI}_{\mathrm{O}_{2}}$ was raised.

Figure 3 compares the measured intervals to their respective awake control studies for both groups. In Group 1 , the $Q S_{2}$ interval in the enflurane control studies was significantly different from the awake control $(p<0.05)$. During enflurane pressor studies LVET was decreased and PEP increased significantly from the awake control in both groups.

For the derived intervals there were significant changes from the $A C$ during the EP studies in both groups for PEP/LVET, $1 / \mathrm{PEP}^{2}$, and ejection fraction, indicating a decrease in myocardial performance with pressure elevation (Figures 4-6). In addition, in Group 1, 1/PEP ${ }^{2}$ during the enflurane control was decreased significantly from the awake pressor value. In Group 2, the enflurane pressor value for $1 / \mathrm{PEP}^{2}$ was significantly decreased from the awake pressor and the enflurane control as well as the awake control.

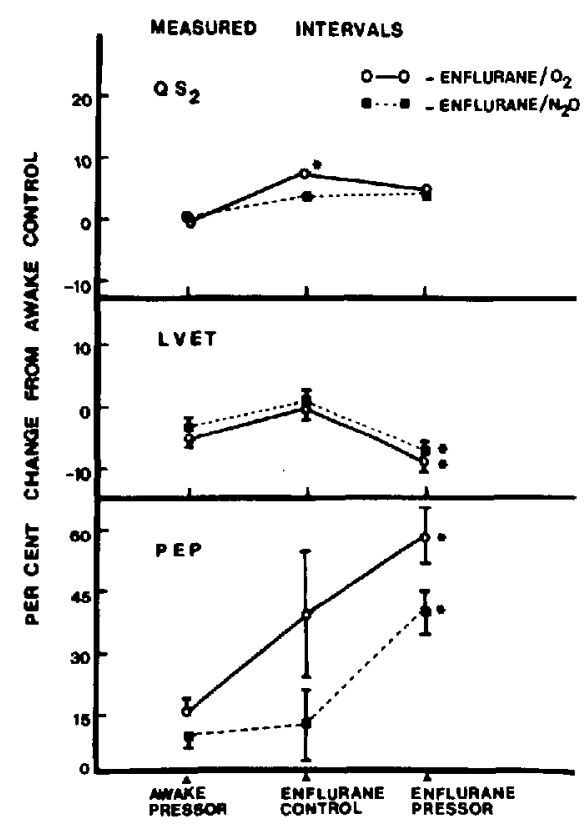

FIGURE 3 Measured systolic time intervals (STI) comparing the awake pressor (AP), enflurane control (EC) and enflurane pressor (EP) expressed as per cent change from awake control (AC) for both groups. Note the significant difference from $A C(p<0.05)$ during the EC studies for $\mathrm{QS}_{2}$ and during the EP studies for LVET and PEP.

There were no significant differences between the Group 1 and Group 2 subjects for the measured or derived indices.

\section{Discussion}

Our data show that in the unanaesthetized subjects there were essentially no changes in the indices of myocardial performance after the 


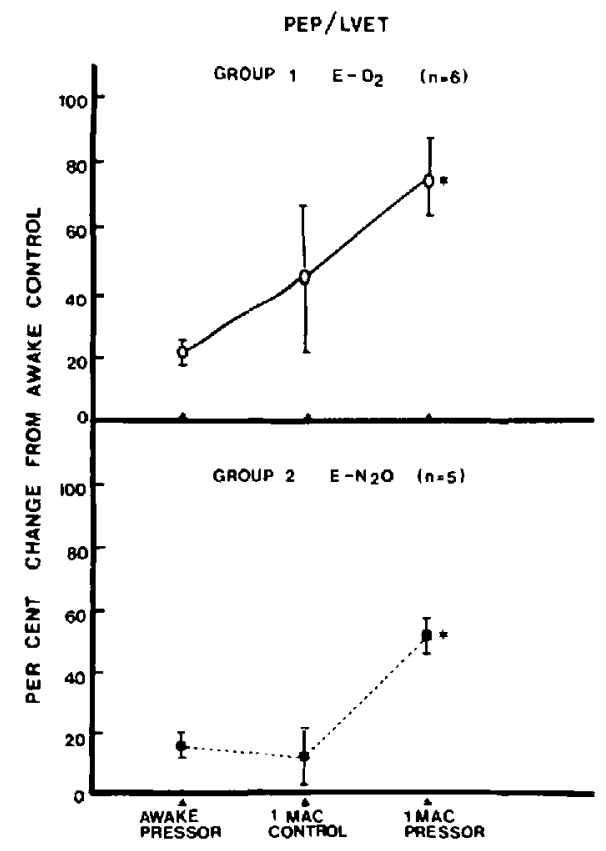

FIGURE 4 Comparison of PEP/LVET to awake control (AC) expressed as a percentage for awake pressor (AP) enflurane control (EC) and enflurane pressor (EP) for both groups. Significant increase $(p<$ 0.05 ) was observed only during EP studies.

injection of angiotensin. Similarly, Ross and Braunwald observed that in subjects with normal left ventricular function, the stroke volume was maintained with increased pressure. ${ }^{2}$ In contrast, when our subjects were anaesthetized to equipotent levels of enflurane or enflurane nitrous oxide anaesthesia, myocardial performance was significantly depressed when systemic pressure was increased. Similarly, in subjects with depressed left ventricular function, Ross and Braunwald observed that increasing vascular resistance resulted in an actual decrease in stroke volume and ejection fraction. ${ }^{2}$ This was associated with significant increases in left ventricular end-diastolic pressure and a decrease in the extent and rate of muscle fibre shortening; that is, their ventricular function curves exhibited decending limbs.

The ability of the normal undepressed heart to maintain a normal stroke volume in response to a sudden increase in outflow resistance has been attributed to either the Frank-Starling effect or the "Anrep" effect. 2,11,12 The "Anrep" effect or homeometric autoregulation is characterized by

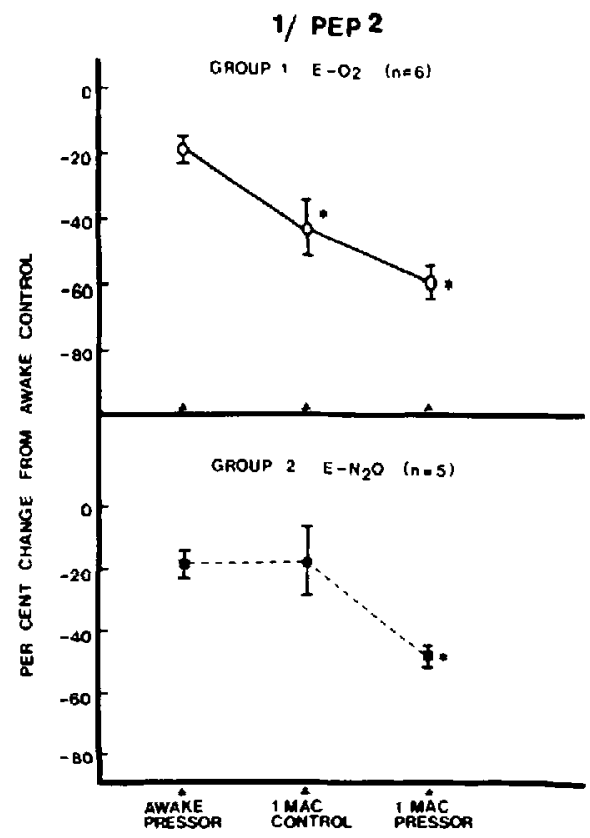

FIGURE 5 Comparison of (1/PEP $\left.{ }^{2}\right)$ to the $A C$ (expressed in per cent change) for AP, EC, and EP. In both groups there were significant differences $(p<$ 0.05 ) during the EP studies. In group 1 subjects of 1/PEP ${ }^{2}, E C$ was different to AP. In group 2, EP was different from $A C, A P$ and $E C(p<0.05)$.

an increase in the intrinsic contractility of the myocardium with a decrease in ventricular size and left ventricular end-diastolic pressure when outflow resistance is increased; that is there is a positive inotropic response to the increase in impedence. Strong arguments against this mechanism being of any significance have been presented by Sonnenblink and Downing ${ }^{13}$ and Vatner. ${ }^{14}$ Furthermore, Monroe, et al. have shown that the increase in positive inotropism following increased vascular impedence represents recovery of the myocardium from temporarily induced subendocardial ischaemia due to the pressure rise, the recovery being associated with coronary autoregulation. ${ }^{15}$ In view of this, we feel that the decrease in myocardial performance in our anaesthetic studies represents a failure of the Frank-Starling mechanism or heterometric autoregulation.'

Could the decrease in myocardial performance in our studies be induced by baroreflex response to the increase in systemic pressure? Vatner, et al. have shown that although the baroreflex has a very significant effect on heart 


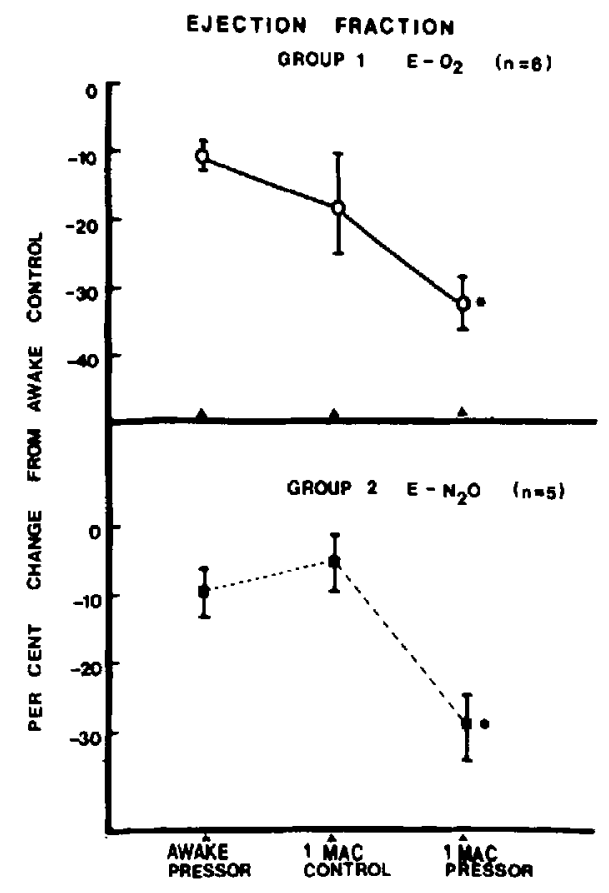

FIGURE 6 Comparison of ejection fraction to the $A C$ (expressed as per cent change) for the AP, EC and EP studies. Significance $(p<0.05)$ was observed only during the EP for both groups.

rate, its control over myocardial contractility is of minor significance. ${ }^{17}$ Our data support their observations in that despite very significant changes in heart rate during the awake control studies, there were essentially no significant changes in the indices of myocardial performance. In addition, we have previously shown that anaesthesia with enflurane and enflurane with nitrous oxide depresses the baroreflex significantly. ${ }^{16}$ Therefore, we cannot attribute the decrease in myocardial performance seen in our studies to a reflex-induced depressive effect on the myocardium from an increase in systemic pressure.

To our knowledge, there are no other reports observing the interaction between enflurane anaesthesia and increase of systemic pressure. However, halothane has been shown to have an effect similar to enflurane. In dogs with the chest open and anaesthetized with halothane, PrysRoberts observed that increased impedance resulted in a moderate decrease of stroke output of the ventricle. ${ }^{3}$ In a human study, Filner and Karliner showed that patients with depressed ventricular function curves from halothane anaesthesia responded to increased after-load (neosynephrine) by a further depression of myocardial function. ${ }^{4}$ Afterloading has been shown to affect stroke output significantly in two poorly controlled clinical studies with narcotics, alone or in association with nitrous oxide. ${ }^{18,19}$

In our studies, the doses of angiotensin used to increase peripheral vascular resistance has been shown to have little direct effect on the myocardium $^{11}$ and produces less change in venous tone than is seen with other clinical pressor agents. $^{2}$

We chose a noninvasive method of assessment of myocardial performance. In most instances the use of systolic time intervals has been shown to correlate closely with more direct measurements of ventricular function. The relationship between systolic time intervals and their derivations, with various physiological and pharmacological interventions, has been reviewed in detail by Weissler and Garrard. ${ }^{8}$ Filner and Karliner have shown that, with pressure elevation during 1.2 MAC halothane anaesthesia, there were good correlations between invasive and noninvasive measurements; ${ }^{4}$ however, their data became less reliable as anaesthetic depth was increased. Our studies were done at the $1 \mathrm{MAC}$ level of anaesthesia.

When the subjects in both groups were anaesthetized, there were significant drops in blood pressure from the awake control $(p<0.05)$. It is significant that during anaesthesia the pressure level achieved with angiotensin was in the normotensive awake pressure range for each subject. This return of systemic pressure to awake levels resulted in deterioration of myocardial performance, whereas in the awake studies there was no decrease in performance when pressures were increased to the hypertensive range.

The clinical relevance of these studies is that, during enflurane anaesthesia, there are many occasions when there is an acute increase in arterial blood pressure (tracheal intubation, surgical incision, cross clamping of the aorta, etc.). Increases in peripheral resistance would result in a decrease in myocardial performance in these circumstances. The data are particularly relevant in those subjects who have hypertensive cardiovascular disease or myocardial ischaemia, in which myocardial performance is already compromised. In addition, pressor agents which increase systemic vascular resistance should be used with caution in indjviduals anaesthetized 
with enflurane because the added stress of increased afterload could further compromise cardiac output severely.

\section{REFERENCES}

1. MAsoN, D.T. Afterload reduction and cardiac performance. Physiologic basis of systemic vasodilators as a new approach in treatment of congestive heart failure. Am. J. Med. 65; 106-125 (1978).

2. Ross, J. \& Braunwald, E. The study of left ventricular function in man by increasing resistance to ventricular ejection with angiotensin. tance to ventricular ejection with
Circulation 29: $739-749$ (1964).

3. Prys-Ronerts, C., Gersh, B.J., Baker, A.B. \& REUBEN, S.R. The effects of halothane on the interactions between myocardial contractility, aortic impedance, and left ventricular performance. I: Theoretical considerations and results. Brit. Jour. Anaesth. 44: 634-649 (1972).

4. Filner, B.E. \& Karliner, J.S. Alterations of normal left ventricular performance by general anesthesia. Anesthesiology 45:610-621 (1976).

5. Eger, E.I., Smith, N.T., Stoelting, R.K., et al. Cardiovascular effects of halothane in man. Anesthesiology 32: 396-409 (1970)

6. Smith, N.T., Calverley, R.K., PrysRoberts, C., Eger, E.I. \& JoNes, C.W. Impact of nitrous oxide on the circulation during enflurane anesthesia in man. Anesthesiology 48 . flurane anesthesia

7. Calverley, R.K., SMITH, N.T., PrysRoberTs, C., Eger, E.I. \& Jones, C.W. Cardiovascular effects of enflurane anesthesia during controlled ventilation in man. Anesth. Analg. 57: 619-628 (1978).

8. Weissler, A.M. \& Garrard, C.L. Systolic time intervals in cardiac disease. Modern concepts of Cardiovascular Disease. 60: 1-8 (1971).

9. Reitan, J.A., SMith, N.T., et al. The cardiac pre-ejection period. Anesthesiology 36: 76-80 (1972).

10. GarRard, C.L., Weissler, A.M. \& DodGe, H.T. Relationship of alteration in systolic time intervals to ejection fraction in patients with heart disease. Circulation 42: 455-462 (1968).

11. ANREP, G. On the part played by the suprarenals in the normal vascular reactions of the body. J. Physiol. (Lond.) 45: 307 (1912).

12. SARnoff, S.J., Mitchell, J.H., Gilmore, J.P. \& REMENSNYDER, J.P. Homeometric autoregulation in the heart. Circ. Res. 8: 1077 (1960).

13. Sonnenblink, E.H. \& Downing, S.E. Afterload as a primary determinant of ventricular performance. Am. J. Physiol. 204: 604-610 (1963).

14. Vatner, S.F. \& Braunwald, E. Cardiovascular control mechanisms in the conscious state. N. Eng. Jour. Med. 293: 970-976 (1975).

15. Monroe, R.G., Gamble, W.J., et al. The Anrep effect reconsidered. J. Clin. Invest. 51: 2573-2583 (1972).

16. Morton, M., Duke, P.C. \& ONG, B. Baroreflex control of heart rate in man awake and during enflurane and cnflurane-nitrous oxide anesthesia. Anesthesiology 52: 221-223 (1980).

17. Vatner, S.F., Higoins, C.B., et al. Extent of carotid sinus regulation of the myocardial contractile state in conscious dogs. J. Clin. Invest. 51: 995-1008 (1972).

18. Schauble, J.F., Wender, R.H., et al. Sensitivity of the left ventricule to outflow resistance. Anesthesiology 51: \$107 (1979).

19. Mongano, D.T. Effects of afterload on ventricular performance. Anesthesiology 53: \$110 (1980).

\section{RESUME}

La performance myocardique lors d'une élévation subite de la tension artérielle, telle qu'évaluée par des moyens non invasifs a été étudiée sur onze sujets en bonne santé, éveillés et ensuite anesthésiés avec des doses équivalentes (1 MAC) soit d'enflurane (groupe 1) ou d'enflurane avec protoxyde d'azote 70 pour cent (groupe 2 ). Sous cette anesthésie, on a observé une diminution significative et égale des indices de performance myocardique $(\mathrm{P}<$ 0.05 ) dans les deux groupes avec élévation tensionnelle lorsqu'on les compare aux contrôles de sujets éveillés. Les résultats sont identiques à ceux qu'on a déjà observé sur des sujets dont la fonction myocardique est déprimée par une maladie cardiaque ischémique ou l'anesthésie à l'halothane. 